\title{
Transformation towards a Smart Maintenance Factory: The Case of a Vessel Maintenance Depot
}

\author{
Gwang Seok Kim * and Young Hoon Lee \\ Department of Industrial Engineering, Yonsei University, 50 Yonsei-ro, Seodaemun-gu, Seoul 03722, Korea; \\ youngh@yonsei.ac.kr \\ * Correspondence: kimks747@yonsei.ac.kr
}

check for updates

Citation: Kim, G.S.; Lee, Y.H.

Transformation towards a Smart Maintenance Factory: The Case of a Vessel Maintenance Depot. Machines 2021, 9, 267. https://doi.org/ $10.3390 /$ machines 9110267

Academic Editors: Zhuming Bi, Li Da $\mathrm{Xu}$ and Puren Ouyang

Received: 31 August 2021

Accepted: 30 October 2021

Published: 2 November 2021

Publisher's Note: MDPI stays neutral with regard to jurisdictional claims in published maps and institutional affiliations.

Copyright: (C) 2021 by the authors. Licensee MDPI, Basel, Switzerland. This article is an open access article distributed under the terms and conditions of the Creative Commons Attribution (CC BY) license (https:/ / creativecommons.org/licenses/by/ $4.0 /)$.

\begin{abstract}
The conceptualization and framework of smart factories have been intensively studied in previous studies, and the extension to various business areas has been suggested as a future research direction. This paper proposes a method for extending the smart factory concept in the ship building phase to the ship servicing phase through actual examples. In order to expand the study, we identified the differences between manufacturing and maintenance. We proposed a smart transformation procedure, framework, and architecture of a smart maintenance factory. The transformation was a large-scale operation for the entire factory beyond simply applying a single process or specific technology. The transformations were presented through a vessel maintenance depot case and the effects of improvements were discussed.
\end{abstract}

Keywords: smart factory; smart process transformation framework; smart maintenance architecture; smart maintenance factory

\section{Introduction}

A smart factory is a production plant where the pillars of Industries 4.0 are implemented, including additive manufacturing (3D printing), augmented reality (AR), Internet of Things (IoT), big data analytics, autonomous robot, simulation, cyber-security, vertical and horizontal integration, and cloud computing [1]. The concept of a smart factory has become a keyword of manufacturing sites along with the technological development during the fourth industrial revolution.

Hyundai Heavy Industries, Daewoo Shipbuilding \& Marine Engineering Co., Ltd., and Samsung Heavy Industries are the three major global ship manufacturers in Korea that lead smart ship and yard constructions by applying the new technologies of the fourth industrial revolution and utilizing IT systems [2]. In the report by SPAR Associates. Inc., which have been serving in the shipbuilding and repairing industry for over 45 years, about $23 \%$ of the total cost is ship acquisition cost, approximately $35 \%$ is labor cost, and the remaining $42 \%$ is repairing and maintenance in the Naval Ship Life Cycle Cost (LCC) Model [3]. Although the growth of a smart factory is limited to the ship building phase, shipbuilders are interested in further expanding the smart factory concept to the service phase in order to expand the scope of the maintenance, repair, and operations (MRO) business. It is necessary to expand the research on manufacturing-oriented smart factory research to cover the entire lifecycle.

This study takes focus on a practical case that expands the entire ship lifecycle from build phase to service phase, as shown in Figure 1.

The adaptability of the concept of a smart factory to a repair and maintenance factory (hereafter referred to as a maintenance factory) requires an understanding of the differences at work. Ship building is the process of assembling modules produced in factories and yards in accordance with the job schedule, whereas repair and maintenance tasks usually do not follow a fixed assembly process plan. Repair and maintenance work has the following variabilities: 


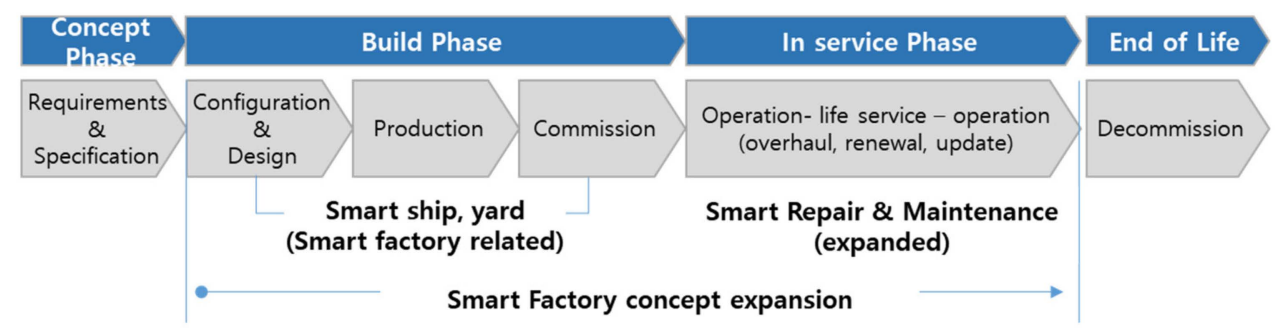

Figure 1. Ship lifecycle and smart factory expansion.

Variability in the plan: Ship building is progressed step by step following the working plan, and the supply of each relevant component is proceeded on a planned basis. In contrast, unplanned repair and maintenance requirements frequently occur since failures of ships are unpredictable. Moreover, repair and maintenance plans may vary due to the dock's idle state because ships must be drawn on the dry dock.

Variability in the process: The process of ship building is usually done at fixed workplaces and workstations. However, the process of repair and maintenance include: draw the ship to the dry dock - take away parts from the ship — taking parts out from the shipmoving to the factory—disassembling parts—cleaning — repairing-reassembling — testing performance-moving from the factory to the ship-taking in to the ship-assembling on the ship-trial run. The required jobs in the repair and maintenance process to repair/replace defective parts and improve performance are different from jobs in the ship building process.

Variability in the time: Planned demand and standard working hours are set for production and manufacturing. However, the work time of repair and maintenance varies depending on the degree of failure and repair requirements. Because the delivery date of each part is different (e.g., discontinued parts or parts that have a long delivery period), repair and maintenance are hard to complete in a timely manner.

Variability in the workplace: In the case of ship manufacturing, the parts are first assembled in the factory and then at the yard. On the other hand, repair and maintenance are not only proceeded in the factory; the process may be done on the ship or through remote maintenance system as needed.

The purpose of this paper is to present a method to extend the smart factory concept of the build phase to the service phase through empirical examples. Smart transformation procedure, the framework, and architecture were developed by repeating revisions and improvements in the process of establishing a smart transformation plan for about one year.

The four contributions of this study are as follows. First, this study provides the transformation procedure for a smart maintenance factory. Second, this study developed a smart process transformation framework for building a smart maintenance factory to improve highly volatile processes. Smart transformation occurs when site workers understand strategies and voluntarily draw actual changes. To this end, this study developed a practical template for site workers to participate in change and present their opinions. Third, this study proposed the architecture of a smart maintenance factory that shows the future look of a smart maintenance factory. This study suggested the value and technology for transforming an existing factory to a smart repair and maintenance factory while giving consideration to the characteristics of the process. Finally, smart transformation was implemented for the vessel maintenance depot. Transformation is a large-scale operation that changes the entire factory beyond simply applying a single process or specific technology.

The remainder of this paper is composed as follows. Section 2 reviews previous studies, Section 3 introduces the materials and methods, Section 4 presents the application cases, and in Section 5, we discuss the results, address the conclusions, and suggest directions for further research. 


\section{Literature Review}

This study reviewed previous studies and categorized them into a practical application and research extension from ship building phase to ship servicing phase. Research of the building phase could be divided into smart manufacturing for the production process, smart management by information, and smart maintenance for $5 \mathrm{M}+1 \mathrm{E}$ (Man, Machine, Material, Method, Measurement, and Environment), which supports production, as shown Figure 2 .

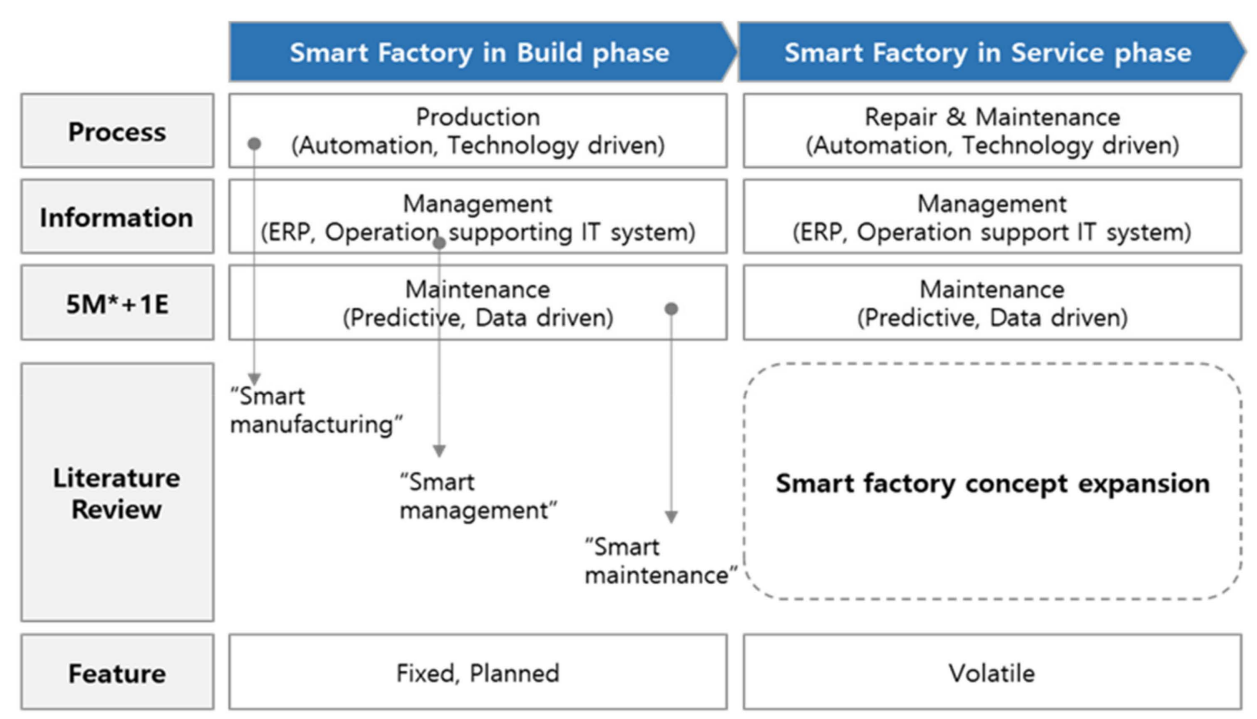

*man, machine, material, method, measurement, and environment

Figure 2. Research on smart factory and expansion.

Among numerous studies conducted in each area, the concept, the recent direction, and research on the implementation will mainly be analyzed.

Smart manufacturing is a term coined by several agencies such as the Department of Energy (DoE) and the National Institute of Standards and Technology (NIST) in the United States. It highlights the use of information and communication technology (ICT) and advanced data analytics to improve manufacturing operations on the shop floor $[4,5]$, factory [6], and supply chain $[7,8]$.

Smart manufacturing incorporates various technologies, including cyber-physical production systems (CPPS), IoT, robotics/automation, big data analytics, and cloud computing to realize a data-driven, connected supply network [9]. Intelligent manufacturing has often been used synonymously with smart manufacturing. Technologies and enabling factors associated with smart manufacturing were reviewed to compare the differences between smart manufacturing and intelligent manufacturing $[4,10,11]$. Studies on the features and availability of smart manufacturing and intelligent related technologies were carried out [12]. Compared to smart manufacturing, intelligent manufacturing focuses more on the technological aspect and less on the organizational aspect.

The opportunities and organizational issues to be considered during smart transformation were analyzed for SMEs [13]. A smart manufacturing performance measurement system was introduced based on exploratory and empirical research [14]. According to these studies, a guide for investment in smart manufacturing was presented to ensure the validity of investment. This study used a top-down approach to introduce the specific implementation scheme from top-level planning for industrial practice in smart manufacturing [15].

By referring to the studies of smart maintenance in the build phase, the applicability and implications for the service phase were examined. We analyzed the latest research on a smart maintenance concept, the changing trend of the existing IT system, recent intensive predictive maintenance studies, and maintenance architecture. Smart maintenance was 
defined as based on four main components through expert interviews and preliminary research on manufacturing plants. The four main elements are data-driven decisionmaking, human capital resources, internal integration, and external integration [16]

The Enterprise Resource Planning (ERP) system, which manages materials, budget, and planning, and the Manufacturing Execution System (MES), which manages field data, are the two representative factory management systems to support production. When a traditional factory is transformed into a smart factory, the existing ERP and MES systems would be advanced by applying cloud technology, big data-based data diagnostic, and AI technology. The existing information management systems of smart factory processes require more flexibility and a larger volume of data, which needs to connect to related systems, to analyze, and to visualize the activities inside the organization $[14,17,18]$. The introduction of AI systems that support decision making by making knowledge of the production process between each system and data collected from various smart devices is spreading $[15,19]$.

In addition to academic research, the technology trends suggested by the operators in the maintenance industry were analyzed and reflected in this study. The five transformational Trends Reshaping Industrial Maintenance [20] are: (1) Additive (3D printing) Manufacturing in Maintenance, U.S. Department of Transportation to publish a notice which aims at raising awareness about the use of Additive Manufacturing in the maintenance, and preventive maintenance areas; (2) Internet of Things, Wireless Sensor Networks, and IoT-based automated data collection increases workers' productivity; (3) Augmented Reality (AR) for Training and Remote Maintenance. AR is enabling new paradigms for maintenance, including remote maintenance and maintenance customized to the workers' under-standing and skills; (4) Maintenance as a Service (MaaS) could become a game changer in industrial maintenance. It can motivate machine vendors to provide the best service while also providing versatile, reliable, and functional equipment; (5) Supply Chain Collaboration. Streamlining the supply chain management information has been proven to be extremely beneficial for industrial maintenance as well, as it reduces the delivery times for parts. At the same time, supply chain operators benefit from maintenance insights, such as predictive maintenance.

The other operator of Manufacturer [21] stated that ERP and MES should be datadriven management solutions to support Industry 4.0 as follows: (1) Modern ERP systems must be built fundamentally different from the ground up; (2) The ERP system should also be architected to interact with external systems with application programming interfaces (APIs) available for any and all entities of the system; (3) IoT should be able to make almost any product a smart, connected product. IoT operations support traditional MES for shop floor automation and control adding the flexible communication and data collection protocols. The research theme of smart maintenance is changing from Time Based Management (TBM) to Condition-Based Maintenance (CBM) [22] for predictive maintenance and research on optimizing preventive intervention through CBM [23]. Studies on collaborative-based architecture [24], web platform [25], decision support [26], sensor and data analysis for predictive maintenance were discussed for CBM [27].

A study on the basics for designing the maintenance process of Industry 4.0 [28] and a study on performance and KPI design are also presented [29]. SMEs do not exploit all the resources for implementing Industry 4.0 and often limit themselves to the adoption of Cloud Computing and the IoT [30,31]. These limitations will be experienced not only in this study but also in most organizations.

In order to expand the smart factory concept to the service phase, practical application research, and applications were emphasized $[6,7,32]$. The difficulties in applying the concept of a production-oriented smart factory to a smart factory in the maintenance area were discussed by site workers. The staff of vessel maintenance depot stated the limitations in applying smart factory to the field of repair and maintenance sector. "Despite the rapid growth of technology due to the fourth industrial revolution, smart factories are applied in the maintenance field, not the manufacturing field, but in reality, there are technical 
limitations. Since nobody has ever done it, no one has been able to strongly suggest to what extent it should be specified or what is needed to realize the future of the smart vessel maintenance depot. [33], (p. 30)."

We reviewed the smart factories for the ship building phase, including the smart manufacturing, management, and maintenance of a smart factory and the need for research expansion in the service phase. The previous studies on the procedure, modeling, and architecture to build a smart maintenance factory were also reviewed.

Reference [34] presented a step-by-step methodology for the efficient planning of a smart factory from the initial idea to the final realization in the real environment. The construction process from design, smart machining, smart monitoring, smart control, smart scheduling, industrial applications, and the phases of data utilization were introduced [35]. The importance of stepwise starting from a small scale were argued $[36,37]$. The new technology application in a limited area were demonstrated by building a smart factory [38]

Existing studies introduced different models for the smart factory model. Reference [39] proposed a human-centered model, [40] suggested IoT-based, [41] proposed IoT and cloud computing, and [35] proposed a cloud-based control system as smart control systems. Operation values are defined based on the environment and work of the maintenance factory. Reference [42] provided an overview of these principles in terms of the general scope of Industry 4.0, and [7] investigated and analyzed the principles of a smart factory and proposed modularity, interoperability, decentralization, virtualization, service orientation, and real-time capability. Reference [36] suggested features of connectivity, optimization, transparency, proactivity, and agility for smart factory construction.

Different studies on smart factory architecture were presented. Reference [24] introduced a data-based smart maintenance architecture and reference model to perform predictive equipment maintenance in a factory. Reference [43] described the three major criteria of the general system architecture, including mechatronic changeability, individualized mass production, and internal/external networking. Product, production layer, supply layer, integration layer, and IT are defined as the five layers. Reference [44] emphasized the integration of industrialization and informatization as the core of China's smart manufacturing implementation strategy and proposed the standards framework and reference architecture of a smart factory. Reference [45] presented a technical architecture and argued that the interoperability of the systems or components of the architecture at every level is imminent. References [46-48] proposed the hierarchical architecture of a smart factory including four layers, namely the physical resource layer, network layer, data application layer, and terminal layer.

\section{Materials and Methods}

As suggested in previous studies, starting on a small scale [36,37] or limited area [38] seems to be an effective way to minimize risk, but there may be situations in which it is stopped or scaled down due to various obstacles in the process. Procedures for smart conversion of specific tasks are limited in their application of transforming the entire plant. Few studies suggested a method for the procedure for building a smart maintenance factory in the field. We developed a hybrid procedure that combines the top-down procedure that presents the future image and goals of a smart maintenance factory and the bottomup procedure that reflects on the site conditions and requirements for changes. After approximately one year of revision and improvement, this procedure was eventually developed as shown in Figure 3 


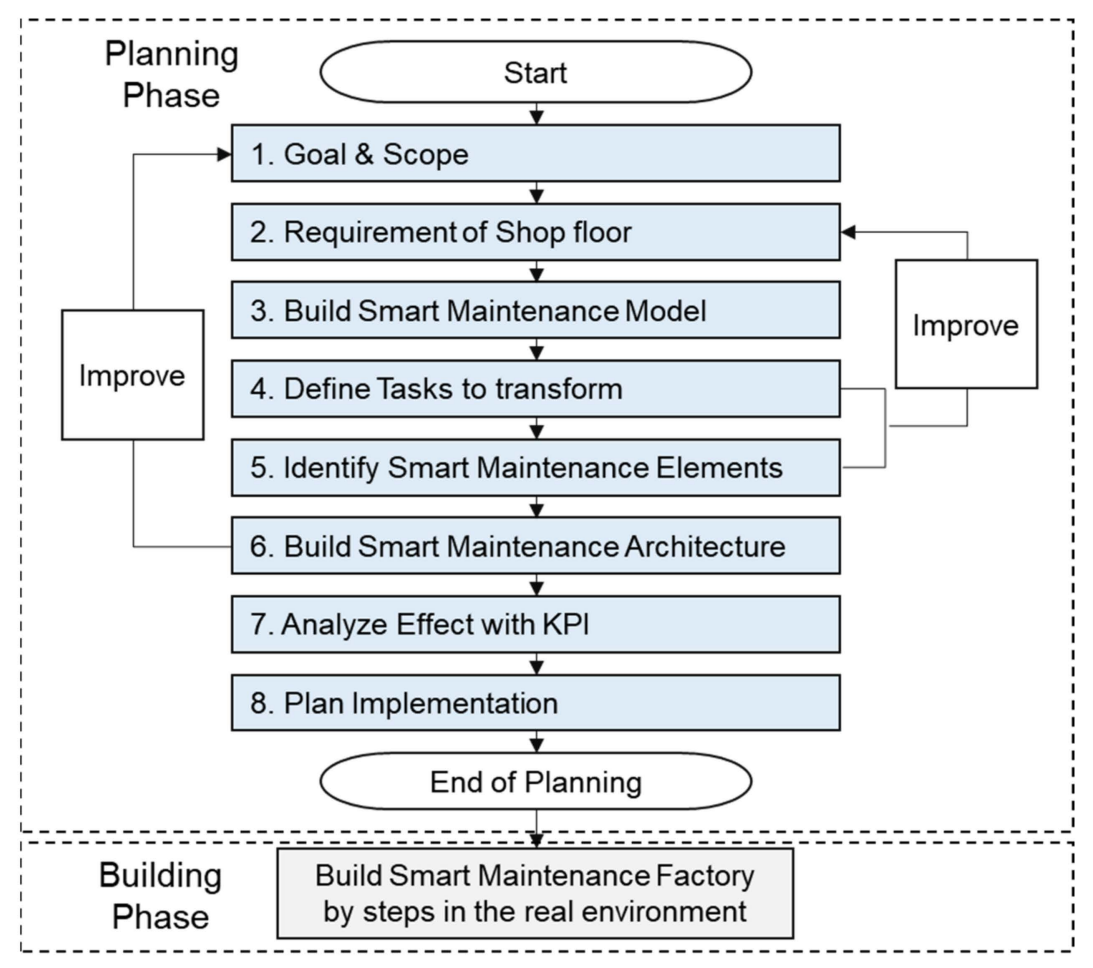

Figure 3. Implementation procedure.

\section{(1) Goal and Scope}

It is desirable to set the goal of a smart maintenance factory based on the organization's missions or policies, instead of the goal of an individual task or technology. In general, the primary goal of maintenance factory management is to minimize variability, which is a characteristic of maintenance, in order to complete the maintenance on time. The safety of workers, jobs on the site, and the quality of maintenance could be ensured. Another important goal is to increase the availability of ships. As a large-scale investment, increasing availability is compared to increasing the value of investment.

(2) Requirements of Shop Floor

The requirements of transforming each workplace of the maintenance factory to a smart factory are analyzed for selecting tasks to be improved. Such transformation requirements are handled systematically based on the smart process transformation framework developed. The characteristic of the smart process transformation framework presented in this study is that it leads to changes in the repair and maintenance process through the following three elements of smart transformation: data, system, and automation (technology).

While the traditional approach derived the necessary elements of data, system, and automation through the direction of process change, the smart process transformation framework in this study intends to lead process change through actual technologies of the fourth industrial revolution. In addition, based on long-term field analysis and opinions from site workers, this study identified that data, IT systems, and automation (technology) take the lead in major changes in smart maintenance plants and thus reflected them in the framework.

As illustrated in Figure 4, the smart process transformation framework is composed of data, systems, and automation (technology) that induce process change. The smart transformation strategy should be defined with KPI and the infrastructure and communication network should be selected to support the smart transformation. The organizational capabilities required for the smart transformation operation should also be planned. 


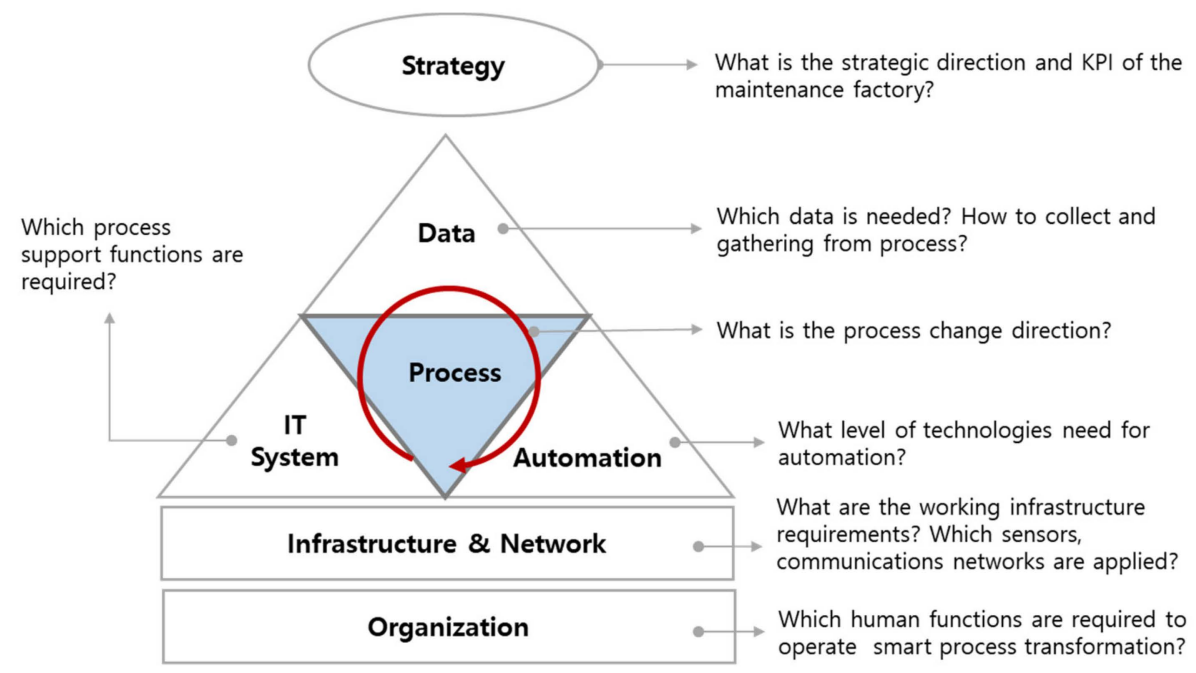

Figure 4. Smart process transformation framework.

Ongoing effort and time are required to obtain the improvement needed from field managers through the smart process transformation framework. Getting new opinions is not easy since most workers and managers are immersed in existing work methods. Thus, it is necessary to provide a specific and convenient template that shows the transformation direction to figure out the challenges to change the viewpoints of site workers and managers. The template effectively helps derive the requirements of the site and encourage participation of the working site. Figure 5 illustrates the template for concretization of changes on the site, which reflects the elements of the smart process transformation framework.

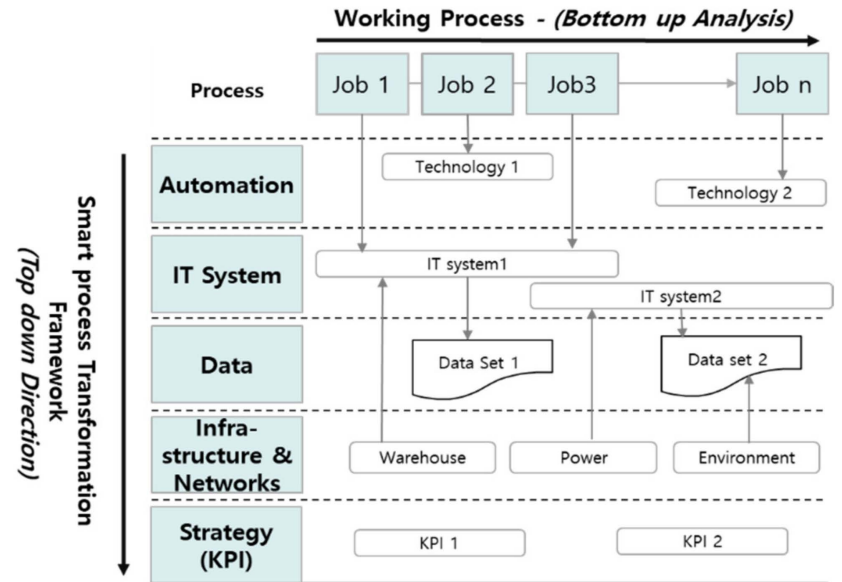

Figure 5. Template for analysis of on-site requirements.

The template consists of the working process on the horizontal axis and the smart transformation framework shown in Figure 4 on the vertical axis. The requirements for jobs constituting the process are classified and organized into automation, IT system, data, operating infrastructure and communication network, and strategy. Automation describes smart technologies and equipment needed for smart transformation. In the IT system, the requirements and functions of the operation support system that support the job are described. Data describes the required data set and format. Support infrastructure requirements such as warehouse and power system are described as infrastructure, and requirements for sensors and communication networks are described in network. Strategies are described in connection with improvement effects in each job and KPIs. In addition, deletion, and integration of jobs in the process are also described. 
Workers on the site are sensitive to organizational changes and may consider the transformation towards a smart maintenance factory a negative effect on job stability [30]. It is a reaction that can be easily felt in the field. Thus, it is recommended not to ask workers on the site for opinions on changes in organization and manpower.

\section{(3) Building Smart Maintenance Model}

The model of a smart maintenance factory is according to the requirements on changes to be made in strategic direction and operational values. Studies have introduced different models such as a human-centered model [39], IoT-based model [40], and cloud computing $[35,41]$ for a smart factory. Principles were suggested, such as modularity, interoperability, decentralization, virtualization, service orientation, real-time capability, connectivity, optimization, transparency, proactivity, and agility for smart factory construction $[7,36]$.

The smart maintenance factory model consists of missions, a target model, operational values, and the technology enabling the technologies of the fourth industry revolution for process transformation. The target model of a smart maintenance factory can be defined in various shapes by integrating the as-is state and strategic direction. When defining the smart maintenance model, it is important to consider how to respond to variability, which is a characteristic of maintenance work. Agile response, predictive, and readiness should be defined as core operating values in order to respond to changes in the work plan, process, time, and workplace of repair and maintenance work.

As an enabling technology for realizing operational values, it enables agile response to changes on site through central control and mobile network. For predictive maintenance, operational data of the vessel are collected and analyzed by a big data system. In addition, inventory and work readiness are promoted through on-site operational support IT systems and smart warehouses. These operating values and required enablers can be derived through on-site interviews.

\section{(4) Define Tasks to Transform}

Tasks define the activities required for smart factories to achieve high performance, from policy, process improvement, data improvement, system construction, infrastructure improvement, and organizational change. Defining tasks is necessary in connection with the workload, schedule, budget, and expected effects to be pursued in the future, so an organizational consensus process is required through several meetings. After defining the task, the selection of new technologies and targeting levels to implement the task should be followed.

\section{(5) Identify Smart Maintenance Elements}

It is a step to define specific technological enablers to implement smart transformation with the selected tasks. Enablers consist of changes in maintenance policies, work standards, and the selection of appropriate technologies. The technology enablers consist of ICT systems for managing the working process and necessary $5 \mathrm{M}+1 \mathrm{E}$, automation, data collection, data system for management and analysis, a network that connects data to the entire maintenance factory, a central control system that manages it in real time, and a smart factory infrastructure.

Selecting the right technologies is one of the main tasks for the smart maintenance element. Reference [49] reviewed research on technology selection over the past 20 years to find out various new technologies needed for manufacturing and various methods for technology selection due to the emergence of the fourth industrial revolution. In selecting Industry 4.0 technology, it is recommended that long-term development or selection of unstable technology be avoided. The hasty or wrong technology selection will weaken the overall work productivity of the plant. It is recommended to apply validated and reliable innovative technologies to the field at the initial stage, and to choose a business operator that has sustainable development and maintenance capabilities. As an advanced work, a written confirmation on the time and degree of the technology application should be submitted for applying a particular technology that is required. 
The required technologies and the purpose of utilizing technologies for smart maintenance are referred from smart manufacturing. Reference [50] insisted on end-to-end ICT-based integration between the manufacturing technologies of smart machines, warehousing systems, and production facilities that have developed digitally and feature end-to-end ICT-based integration. Reference [34] mentioned equipment, a cloud-based control system, communication network for real-time data collection and control, and the importance of power monitoring to secure stable operation.

\section{(6) Build Smart Maintenance Architecture}

By configuring the architecture based on the operational values, the future shape of the smart maintenance factory and its implementation technology are identified. The architecture of a smart maintenance factory presents the direction of technical realization for constructing the smart maintenance factory. The architecture may be presented differently by point-in-time, by factory, or by composition direction.

Studies have introduced the data-based smart maintenance architecture [24], the internal/external networking architecture [43], the integration of industrialization and informatization architecture [44], the interoperability technical architecture [45], and the hierarchical architecture of smart factory [46-48].

This study set one offsite layer and six onsite layers to classify the values and required technological elements. The feature of the smart maintenance factory architecture in this study contains seven layers according to the implementation characteristics, and maintenance was divided into factory maintenance and remote maintenance of vessel according to the required services and technologies. It also expressed the connection between business management and field management as shown in Figure 6.

\begin{tabular}{|c|c|c|c|c|c|c|}
\hline \multirow{2}{*}{\multicolumn{2}{|c|}{ Business O\&M }} & Values & \multicolumn{3}{|c|}{ Systems and Technological Enablers } & \\
\hline & & $\begin{array}{l}\text { Business } \\
\text { Value }\end{array}$ & \multicolumn{3}{|c|}{ ERP and Management System } & $\begin{array}{l}\text { Off- } \\
\text { Site }\end{array}$ \\
\hline \multicolumn{2}{|c|}{ Control Layer } & \multirow{7}{*}{$\begin{array}{l}\text { Operational } \\
\text { Values } \\
\text { of On-Site }\end{array}$} & & Deport (Factory) Control System & Remote Control System & \multirow{7}{*}{$\begin{array}{l}\text { On } \\
\text { Site }\end{array}$} \\
\hline \multicolumn{2}{|c|}{ Intelligent Layer } & & & n-site Operating Supporting System & $\begin{array}{l}\text { Remote Maintenance } \\
\text { Supporting System }\end{array}$ & \\
\hline & ata Layer & & & Data Diagnostic System & Data Monitoring System & \\
\hline \multicolumn{2}{|c|}{ Automation Layer } & & \multicolumn{2}{|r|}{ Industry 4.0 Technology Application } & $\begin{array}{c}\text { Industry } 4.0 \text { Technology } \\
\text { Application }\end{array}$ & \\
\hline \multicolumn{2}{|c|}{ Network Layer } & & \multicolumn{2}{|r|}{ IoT \& Communication Network } & IoT \& Communication Network & \\
\hline \multirow{2}{*}{$\begin{array}{l}\text { Shop } \\
\text { Flow }\end{array}$} & Process Layer & & \multirow{2}{*}{ 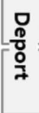 } & Working process & \multirow{2}{*}{ 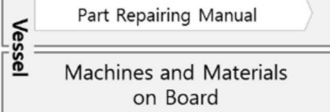 } & \\
\hline & $\begin{array}{c}\text { Infrastructure } \\
\text { Layer }\end{array}$ & & & Common Working Environments & & \\
\hline
\end{tabular}

Figure 6. Architecture of a smart maintenance factory.

The first layer, Business O\&M, is composed of ERP components that emphasize management efficiency. It is composed of systems that share information through the organization, such as scheduling, human resource, budgeting, procurement, etc. The other six layers are field-oriented functions. Operational values such as visibility, stability, and speed should be set to guide the design direction of each layer.

The control, intelligence, data, and network layers transform the visualized and datadriven maintenance factory through close interlocking. The control layer manages risks and fluctuations in the schedule and environment through the central control screen. In the intelligent layer, the field workers want to secure the process visibility of their jobs through the operation support system. In the data layer, the maintenance process is identified by sharing specific data on-site. To this end, it consists of technical elements of data standardization, collection, and sharing. For remote maintenance, the operational conditions are monitored through remote diagnostic and operational supporting system. 
In the automation layer, productivity and safety are focused. It is composed of industry 4.0 technologies applicable to each workplace to secure safety and productivity. The network layer emphasizes connectivity for collecting data and sharing information of workers and materials through wireless and wire. The remote maintenance is connected to the vessel via satellite.

The shop flow emphasizes speed, quality, and safety. The shop flow layer consists of the actual work processes and operational infrastructures. For remote maintenance, the vessel is considered as the shop floor.

\section{(7) Analyze Effect with KPIs}

KPIs and effect analysis are the high priority parts of executing Industry 4.0 technologies in tasks and securing budgets. Reference [51] pointed out the direction, the contents of the role, and the importance of key performance indicators of application Industry 4.0 technologies. Reference [52] demonstrated the expected effect of building a smart factory and analyzed the effect of smart factory adoption with an empirical analysis based on a sample representing local manufacturing units.

It is important to define KPIs based on the missions and operational value of the maintenance factory. Although it is appropriate to present KPIs and the improvements of a single task if a single task-oriented process is applied, it is essential to select the expected effects and KPIs for the maintenance factory if the entire factory is transformed step by step, as presented in this study. Linking KPIs with the expected effects is an operation optimization plan that is done after the establishment of a smart maintenance factory by aligning strategy and implementation.

\section{(8) Plan Implementation}

There are two ways to construct a smart maintenance factory. The first way is to prioritize technology development to evaluate performance and expected effects, and then apply them to the workplace on a technical basis. It is to expand according to the technology development stage. The other way is to select a specific workplace as a pilot, apply all technologies that are under consideration, and then evaluate the performance and deploy the technologies horizontally to other work processes. It is to expand by the organization or process unit.

While the first way has the disadvantage that it requires a long transformation time, failure of technology may also cause failure of the smart transformation. The second way is preferred if the smart maintenance factory needs to constructed in the short term, because members of the organization are guided to participate in the processes, and improvements or difficulties can be identified immediately in the field. Showing step-by-step outputs will be an important factor that accelerates the implementation of smart transformation to ensure enough budgets throughout the process. In the implementation phase, the priority of transformation tasks will be determined according to budget size and urgency.

\section{Application}

The vessel maintenance depot was operated by the owner of a vessel established about 70 years ago, and it is in the process of smart transformation from mechanical and hydraulic maintenance to 3D printers, articulated lifts, and pilot-level remote maintenance. Currently, the smart factory is evaluated as Level 2.0 of mechanization and computerization.

In the vessel maintenance depot, vessels are towed to the dry dock and the broken parts are separated from the vessel to be repaired in the factory. Vessels are sent to the maintenance depot for regular maintenance and emergency repair due to failure. This study derived the requirements for building a smart maintenance factory from more than 20 maintenance processes. The field issues to be improved through smart maintenance factory construction are shown in Table 1 below. 
Table 1. Issues to be transformed in the vessel maintenance depot.

\begin{tabular}{|c|c|c|}
\hline Classification & Issues On Site & Improvement Direction \\
\hline \multirow{5}{*}{ Process } & Need to improve chronic delay in repair parts. & \multirow{5}{*}{ Predictive Maintenance } \\
\hline & Need to improve poor linkage between schedules & \\
\hline & $\begin{array}{l}\text { Need fine-grained management of worker and working } \\
\text { hours }\end{array}$ & \\
\hline & Avoid concentration on maintenance work at a specific time & \\
\hline & $\begin{array}{l}\text { Neutralization of planned schedules by sudden } \\
\text { maintenance }\end{array}$ & \\
\hline \multirow{3}{*}{ Data } & Need information system to share and collect data on site & \multirow{3}{*}{ Data Diagnostic Management } \\
\hline & $\begin{array}{l}\text { Data-based analysis and managing on-site data are required } \\
\text { for predictive maintenance }\end{array}$ & \\
\hline & Need to identify maintenance history on the site & \\
\hline \multirow{6}{*}{ System } & Maintenance knowledge should be secured & \multirow{6}{*}{$\begin{array}{l}\text { Onsite Operation Supporting } \\
\text { /Monitoring }\end{array}$} \\
\hline & $\begin{array}{l}\text { Insufficient support for the on-site maintenance process by } \\
\text { the existing system }\end{array}$ & \\
\hline & $\begin{array}{l}\text { Integrated control and work monitoring system are needed } \\
\text { on site }\end{array}$ & \\
\hline & $\begin{array}{l}\text { Real-time monitoring system is required for safety } \\
\text { management }\end{array}$ & \\
\hline & $\begin{array}{l}\text { Need to check equipment status information for timely } \\
\text { maintenance }\end{array}$ & \\
\hline & Supporting of remote maintenance are increasing & \\
\hline \multirow{6}{*}{ Automation } & Need automation for work safety and reducing work lord & \multirow{6}{*}{$\begin{array}{l}\text { Automation } \\
\text { (safety and productivity) }\end{array}$} \\
\hline & $\begin{array}{l}\text { Need to improvement of workability, convenience, and } \\
\text { safety }\end{array}$ & \\
\hline & $\begin{array}{l}\text { Insufficient quality control and deterioration of quality } \\
\text { control ability }\end{array}$ & \\
\hline & $\begin{array}{l}\text { Technology required to perform precise tasks such as } \\
\text { positioning a ship }\end{array}$ & \\
\hline & $\begin{array}{l}\text { Precise measurement system required for direct production } \\
\text { and quality assurance of manufactured products }\end{array}$ & \\
\hline & $\begin{array}{l}\text { Technology and equipment required to support remote } \\
\text { maintenance }\end{array}$ & \\
\hline Network & $\begin{array}{l}\text { Need for mobile device, sensors, and network for data entry } \\
\text { and automatic data collection in the field }\end{array}$ & IoT \& Mobile \\
\hline \multirow{3}{*}{ Infrastructure } & $\begin{array}{l}\text { Emphasis on additional and emergency power supply } \\
\text { system }\end{array}$ & \multirow{3}{*}{ Safety and Health } \\
\hline & Warehouse needed for immediate supply of inventory & \\
\hline & $\begin{array}{l}\text { Removal of hazardous substances such as hazardous gas, } \\
\text { waste oil, and dust during maintenance. }\end{array}$ & \\
\hline
\end{tabular}

The transformation of a smart maintenance factory is to establish a predictive maintenance process that is to respond to changes in demands and plans above all else. To this end, the current task-oriented management would be transformed to data-oriented management. The central operation supporting system of the management level would be transited to the on-site supporting system including the monitoring system. The automation was expected to reduce the burden of moving heavy parts and to improve work quality from poor precision. The entire maintenance depot would be connected and transformed into a mobile workplace. A safe and healthy work environment was also required in order to respond to environmental regulations. The research in this paper belongs to the design 
stage, not the implementation stage, and the simulation of the expected result is presented as a goal of improvement.

A diagnosis of the current factory at the smart factory level was conducted through years of learning, and the transformation from the existing factory to a smart maintenance factory was confirmed. Nonetheless, the managers of the vessel maintenance depot intended to carry forward the smart transformation of the existing factory, but they are facing practical difficulties in planning to build the smart maintenance factory [33].

(1) Goal and Scope

This goal has been formulated as a unique mission of the maintenance depot. The goal of the maintenance depot is to maintain and improve performance during the life cycle of a vessel, and to improve the productivity of maintenance factory.

(2) Requirement of Shop floor

For each process, field workers were able to present automation, system, data, infrastructure, and expected effects according to the provided template. In addition, some processes were able to be integrate in response to changes. Figure 7 illustrated the practical requirements that were derived by using templates of the smart process transformation framework.

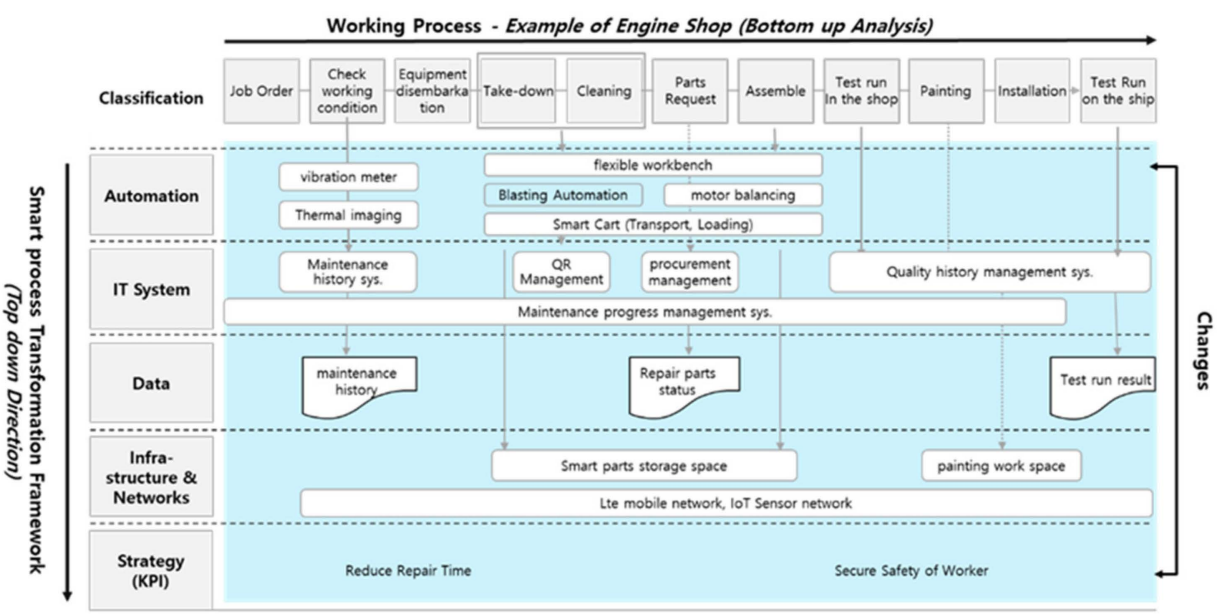

Figure 7. Example of requirements analysis for smart transformation.

(3) Build Smart Maintenance Model

The maintenance depot requests an on-site smart maintenance factory model that can support and manage tasks at the site. The on-site smart maintenance factory is no longer equipment-oriented. Instead, a data-and technology-centered construction direction was born after repeated discussions and strategic presentations. With consideration of the requirements and strategic direction of the derived smart transformation, the strategic model for constructing a smart maintenance factory focuses on two directions.

First, the goals of a data-oriented smart maintenance factory include visualization of the maintenance process and predictive maintenance. Second, the technology-oriented smart maintenance factory is to adopt Industry 4.0 technologies considering job specialty of maintenance.

(4) Define Tasks to Transform

Tasks to build a smart maintenance factory of data driven and technology driven:

Task 1: data diagnostic management;

Task 2: on-site operation support system;

Task 3: semi-automation;

Task 4: remote maintenance system;

Task 5: IoT and mobile workplace; 
Task 6: operational and environmental infrastructure.

The six tasks were determined in consideration of the analyzed issues in the field and the required direction of resolution. In order to implement the six tasks, about a dozen detailed tasks have been embodied. The tasks were finalized through collaboration and considerable time and consultation with managers and the project team.

\section{(5) Identify Smart Maintenance Elements}

Regarding automation and cutting-edge technologies for the smart maintenance factory, Industry 4.0 technologies that suit the specificities of the tasks in a maintenance factory were decided to be applied. Among the various Industry 4.0 technologies, performancevalidated technologies and currently applicable technologies that do not require long development and preparation time were prioritized.

In order to build a data diagnostic management of task 1, the data set must be defined in advance. Since the existing IT system focuses on data storage and loss prevention, the data management for utilization is insufficient. There is a lot of data stored in the system, but usually the data is improper or the data format is incorrect for factual use. It is necessary to establish governance rules for data standardization and collection in the field. The big data system for analyzing a large amount of collected data and Quick Response (QR) for sharing data in the fields are major systems for a data-driven smart factory. The QR system was applied to allow verification of the maintenance history and objects at the site.

In order to implement task 2, the on-site support system is connected to the central management system to share ERP information. It also plays roles of data collection, job history identification, and job processing status on the site. The information of workers, job status, job schedules, working inventories, and dangerous environments on the site can be visually managed through the central control room with a huge screen. The control room ensures comprehensive and rapid response to the various changes on the site.

The cloud-based smart control requires standardized maintenance works and procedures. Standardization is difficult due to variability in the maintenance area. Thus, unlike manufacturing, establishing a separate on-site support system and linking it with the central information and data sharing system may be a method to construct smart maintenance effectively in a short period of time.

For task 3, semi-automation is more preferable to full-automation considering the changeable working conditions. Full automation is recommendable on the basis of a stable work environment, planned work schedules, and repetitive work procedures. Nevertheless, it is not proper to apply full automation to a maintenance factory where works are unstable and highly changeable.

The specific technology for semi-automation was selected in consideration of the working conditions and technology availability. 3D scanning technology for accurately locating a vessel and smart vehicle/cart technology for the convenient movement of workers are selected. For smart moving between processes, smart vehicles were selected as the optimal technology rather than Automated Guided Vehicle (AGV) due to environmental variations, advanced works, and excessive costs. In order to replace discontinued parts, 3D scanning and printing technologies were applied to produce the parts internally without design works. Co-robots are brought onto the site to assemble/disassemble heavy components that need to be repaired, promoting convenience of work. In addition, wearable equipment was introduced to reduce health and safety risks because workers no longer need to manually move heavy weights frequently. CPS (Cyber-Physical Systems) requires digitization of all landmarks of the factory, which takes a considerable amount of time and expense. In this case, a lower-level or simple CPS technologies should be selected. It is not necessary to apply the most advanced Industry 4.0 technologies to build a smart maintenance factory.

In order to implement task 4, an AR system was implemented to support remote maintenance. Workers and managers had a preconceived notion that VR technology shown in the media could change the way of work. However, in order to apply VR technology, it could only be applied to preliminary preparation work and repetitive and limited work 
environments. In addition, there have been studies $[5,15,26,53]$ on the limitations of the application of AR technology to maintenance work in advance. Simple AR technology that can give immediate instructions while sharing a maintenance site through a remote screen was finally selected.

In order to implement task 5: the Internet of Things (IoT) and a mobile workplace, a mobile network based on IoT and Long Term Evolution (LTE) was built as a communication network. The operation condition data of engines and the major equipment of vessels is collected and transmitted through a satellite network in real-time. The data collected from the vessel is diagnosed in the big data system for predictive maintenance. The collected data are aggregated and operated on the IoT platforms and the on-site support system, and are connected to the big data analysis system for predictive maintenance.

To implement task 6, operational and environmental infrastructure, facilities for hazardous substances and the environment from maintenance were built as separate collective facilities. The Energy Saving System (ESS) is equipped for a stable power supply for the increase in power consumption due to the smart maintenance factory.

(6) Build Smart Maintenance Architecture

Figure 8 illustrates the technical architecture for the smart maintenance factory.

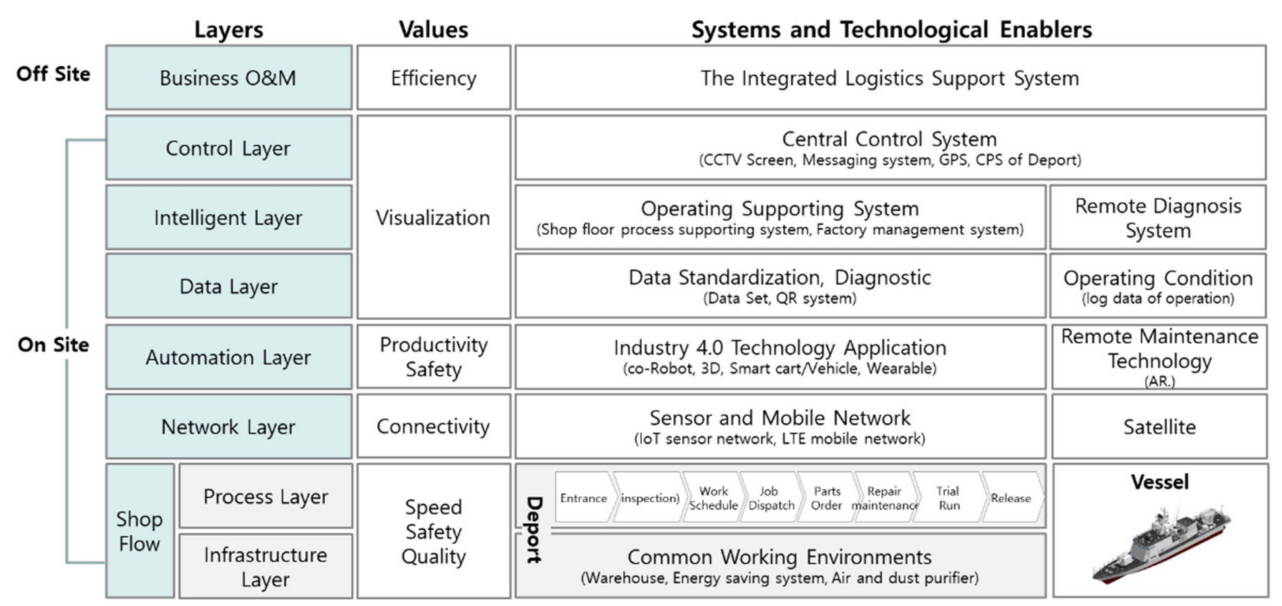

Figure 8. Technology architecture of a vessel smart maintenance factory.

The operating system of a smart maintenance factory promoted the integrated logistics support system of Business O\&M (Operation and Management), for information connectivity between the upper operating system and the on-site operating system. The central control system consists of technologies similar to CCTV technology, such as big screen, location identification, emergency call, remote conference, and messaging technologies. The operating support system (OSS) includes a factory management system and a task management system to support works at the site. The data sets are identified and standardized in type and collection period considering usage from the site. The QR system was applied extensively to most works and materials at the maintenance site. Automation is mainly composed of Industry 4.0 technologies. In this case, semi-automation and ease of movement were focused due the characteristics of the works.

Three types of networks were applied: near distance communication by using IoT, long-range communication via LTE, and remote communication via satellite. The wireless and sensor networks allowed workers to access information conveniently and assured that data created at the field could be collected immediately. Changes that occurred in each work process due to smart data and technology should be carried out in future construction and implementation stages. Acquiring data and technical experts to operate smart factories is another task to be prepared to increase organizational competency in the future.

The operating infrastructure for building a smart maintenance factory is the power supply system. Compared to a traditional machine-centered maintenance factory, a smart 
maintenance factory emphasizes the importance of a stable power supply. Thus, it is essential to build an ESS system to assure an affordable and stable power supply.

Moreover, environmental pollutants such as noise, dusts, gases, and hazardous oil generated during the maintenance process were to be carried out in a separate and safe workplace. Furthermore, a separate smart warehouse was built to store inventory and material for maintenance in order to minimize wait time. For the purpose of promoting a worker use environment with work safety and convenient information utilization, such as PDA terminals, smart helmets, and wearables, the smart maintenance factory was constructed to associate with each technology and system.

\section{(7) Analyze Effect with KPIs}

It is proper to define KPIs based on the missions and operational values of a smart maintenance factory. In this study, the analysis of an expected value requires an analysis of the factory unit. In the case of a single operation, in order to improve the expected effect, an excessive load or performance degradation of related operations may result, and a view of managing the whole is necessary. Aligning KPIs with the expected effects is a plan for operation optimization after the establishment of a smart maintenance factory by linking strategy and implementation.

In connection with the goals of the vessel maintenance depot, the maintenance factory used mean time to failure (MTTF) and mean time to repair (MTTR) as KPIs to increase the availability rate of vessels and improve the productivity of the maintenance factory. Based on the two KPIs, the expected effect was calculated by improving the vessel availability rate and shortening the maintenance time through the establishment of a smart maintenance factory. Through this, the alignment among the Goal-KPI-Expected effect was secured.

While constructing a smart maintenance factory, the question about the benefits of smart transformation has arisen. The Korean Ministry of SMEs and Startups analyzed the effect of smart factory introduction for 5003 SMEs from 2014 to 2017, and as a result, productivity increased by $30 \%$ [54]. The report also provided the results of an application system by companies. In this study, we set improvement goals for each stage and system, based on the empirical productivity improvement effect and the MTTR and MTTF reference values managed internally.

Since this project was in the stage of designing smart transformation, the goal to be obtained in the future was set rather than the actual application result. The goals for each stage are shown in Table 2.

Table 2. Goals of improvement.

\begin{tabular}{|c|c|c|c|c|c|c|c|c|c|c|c|}
\hline \multirow{2}{*}{ Transformation } & \multirow{2}{*}{$\begin{array}{l}\text { Contribution } \\
\text { Weight }\end{array}$} & \multicolumn{5}{|c|}{ MTTR Improvement } & \multicolumn{5}{|c|}{ MTTF Improvement } \\
\hline & & Year0 & Year1 & Year2 & Year3 & Year4 & Year0 & Year1 & Year2 & Year3 & Year4 \\
\hline Big data & $10 \%$ & $0.0 \%$ & $0.6 \%$ & $1.5 \%$ & $2.4 \%$ & $3.0 \%$ & $0.0 \%$ & $0.2 \%$ & $0.6 \%$ & $1.0 \%$ & $1.2 \%$ \\
\hline IoT \& Mobile & $10 \%$ & $0.0 \%$ & $0.6 \%$ & $1.5 \%$ & $2.4 \%$ & $3.0 \%$ & $0.0 \%$ & $0.2 \%$ & $0.6 \%$ & $1.0 \%$ & $1.2 \%$ \\
\hline OSS & $25 \%$ & $0.0 \%$ & $1.5 \%$ & $3.8 \%$ & $6.0 \%$ & $7.5 \%$ & $0.0 \%$ & $0.6 \%$ & $1.5 \%$ & $2.4 \%$ & $3.0 \%$ \\
\hline $\begin{array}{c}\text { Remote } \\
\text { Diagnostic }\end{array}$ & $15 \%$ & $0.0 \%$ & $0.9 \%$ & $2.3 \%$ & $3.6 \%$ & $4.5 \%$ & $0.0 \%$ & $0.4 \%$ & $0.9 \%$ & $1.4 \%$ & $1.8 \%$ \\
\hline Automation & $20 \%$ & $0.0 \%$ & $1.2 \%$ & $3.0 \%$ & $4.8 \%$ & $6.0 \%$ & $0.0 \%$ & $0.5 \%$ & $1.2 \%$ & $1.9 \%$ & $2.4 \%$ \\
\hline Infrastructure & $20 \%$ & $0.0 \%$ & $1.2 \%$ & $3.0 \%$ & $4.8 \%$ & $6.0 \%$ & $0.0 \%$ & $0.5 \%$ & $1.2 \%$ & $1.9 \%$ & $2.4 \%$ \\
\hline $\begin{array}{c}\text { Total } \\
\text { Improvement }\end{array}$ & $100 \%$ & $0 \%$ & $6 \%$ & $15 \%$ & $24 \%$ & $30 \%$ & $0 \%$ & $2 \%$ & $6 \%$ & $10 \%$ & $12 \%$ \\
\hline
\end{tabular}

In this project, when operating the smart maintenance factory for five years, the expected effect was estimated to be up to $30 \%$ for productivity improvement and up to $12 \%$ for vessel operation rate improvement. The total cost of transforming the entire smart maintenance factory was estimated to be about 30 million USD and the expected payback period was three to five years (excluding equipment costs for infrastructure and automation). 


\section{(8) Plan Implementation}

It took about one year to analyze the current status of the existing maintenance factories and establish a construction plan for smart transformation on factory basis, rather than on the particular job or technology basis.

In this study, we transformed by resolving the issues presented in Table 1. The deport of mechanical and hydraulic maintenance feature was transformed to a data-driven and technology-driven maintenance factory. The first change was to establish a data-driven management with data set definition, gathering, analysis, and standardization on the basis of big data governance. Second, QR, IoT (Bluetooth), and LTE-based networks enabled data communication for the entire smart maintenance depot. Third, an on-site operation support IT system was established to support workers, process, and field managers with information and technical support. In particular, in order to secure the visibility of the site, depot, $5 \mathrm{M}$, and environmental status and information were centralized on the central control system. Fourth, a remote data collection system and AR technology were applied for remote maintenance.

Fifth, semi-automation was focused on 3D printing/scanning, Auto Guided Vehicle, and co-Robot to ensure the accuracy of work and the convenience of moving heavy equipment. Finally, a smart warehouse, Energy Saving System, and a workshop for hazardous environments were constructed separately for health and safety. Figure 9 illustrates the changed image of the smart maintenance depot.

The design and developed jobs of the proposed construction plan of the smart maintenance factory will be promoted to ensure that the smart maintenance factory is to be implemented step by step. The pilot working process (shop) was selected and deployed all technologies that were under consideration and will evaluate the performance and deploy the technologies to other work processes over the next five years.

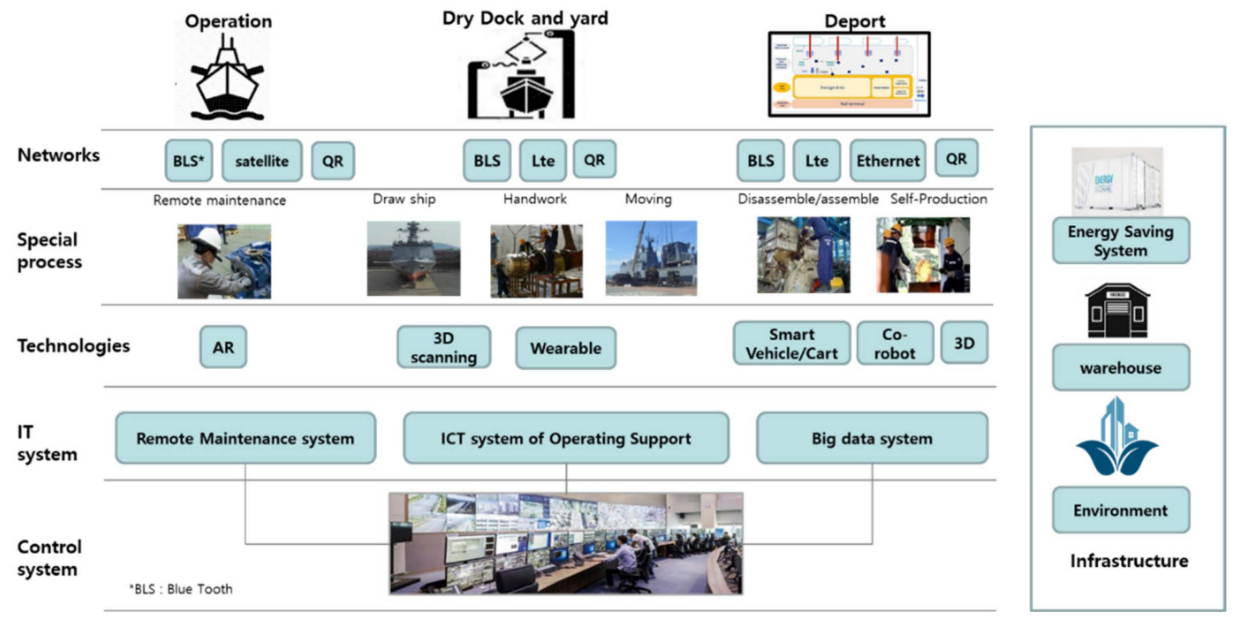

Figure 9. Future image of a transformed smart depot.

\section{Discussion and Conclusions}

In terms of the entire lifecycle, smart factories have been mainly studied in the building phase, and the need to expand research to the service phase has been suggested $[6,7,32]$. This study emphasized the service phase of the smart factory for a vessel maintenance depot. Due to the variability of repair and maintenance work, there was a limit to applying the smart factory concept in the manufacturing field as it is. The procedures and methods were proposed for the smart transformation of maintenance factory by applying Industrial 4.0 technology.

In order to respond to the variability of maintenance works, methods for securing on-site agility and predicting maintenance were presented. For an agile response to the field, we mainly set the direction of visualization on-site to control the processes in line through the visual management and to secure the linkage between each job through the 
on-site operation support system. For predictive maintenance, data of the status of the currently operating vessels was collected in real-time and analyzed by the big data system. The entire maintenance depot was built as a mobile workplace with IoT and LTE enabling data-based factory management.

In data-driven factories, data standardization should be implemented through data governance. Although the goal is to achieve efficient management with big data analysis, the reality is that factories neither collect/manage data nor have a modeling concept for the data. Since the IT system has stored data without considering the data format or type, it has been difficult to utilize the stored data.

The technology-oriented automation was implemented rather than equipment-oriented automation. For automation, semi-automation was proposed rather than full automation considering the work characteristics. Instead of the investment-oriented levels of a smart factory, effect-driven automation should be given the top priority in consideration of the difficulty of learning for operators and the work environment of the factory.

While IT innovation improves the process by applying the necessary technologies and systems, smart transformation changes existing processes through the application of the fourth industrial technologies of data, systems, automation, and infrastructure. In other words, the approach of smart transformation is the opposite perspective to the legacy IT approach.

The concept of a smart factory in the ship building phase needed to be changed for the application of the smart maintenance factory, but most of the technologies including 3D, AR, big data, IoT, and mobile could be accommodated. The applied enablers in the study were IoT system, wireless system, operation support IT system, big data system, remote support system, semi-automation, and infrastructure improvement. Among them, the contribution to improvement was evaluated to be the highest through the operating support system that supports the connection and visualization on-site.

Through the linkage between the mission, KPIs, and expected effect, the goals of smart transformation for the plant rather than the individual work could be carried out. This linkage is considered as a basic strategic direction, enabling the performance-oriented smart maintenance factory operation.

In summary, we conducted a study to expand the smart factory concept, which was limited to the ship building phase and to the ship servicing phase. The smart transformation procedure, framework, and architecture for a smart maintenance factory were proposed with a practical case. The designed practical case was embodied as a data-driven and technology-driven smart factory.

The results of this paper will be a reference model for building a smart maintenance factory in the service area. Future studies should verify the actual increases of MTTFs and reductions of MTTR through smart maintenance factory operation. The expansion and improvement of the approach to business areas other than vessel maintenance could also be studied further.

Author Contributions: Conceptualization, methodology, G.S.K.; supervision, Y.H.L. All authors have read and agreed to the published version of the manuscript.

Funding: This research received no external funding.

Institutional Review Board Statement: Not applicable.

Informed Consent Statement: Not applicable.

Data Availability Statement: Not applicable.

Conflicts of Interest: The authors declare no conflict of interest. 


\section{References}

1. Rüßmann, M.; Lorenz, M.; Gerbert, P.; Waldner, M.; Justus, J.; Engel, P.; Harnisch, M. Industry 4.0 the Future of Productivity And Growth In Manufacturing Industries. BCG 2015, 9, 54-89. Available online: https:/ / www.bcg.com (accessed on 29 August 2021).

2. Kim, D.W.; Lee, H.N. "Smart Ships Are Floating”. Shipbuilders in Korea Taking the Lead in Manufacturing Smart Ships. Available online: http:/ / www.aitimes.com/news/articleView.html?idxno=137618 (accessed on 30 October 2021).

3. Naval Ship Life Cycle Cost (LCC) Model; SPAR Associates, Inc.: New Orleans, MD, USA, 2011.

4. Thoben, K.D.; Wiesner, S.; Wuest, T. "Industrie 4.0" and Smart Manufacturing-A Review of Research Issues and Application Examples. Int. J. Autom. Technol. 2017, 11, 4-16. [CrossRef]

5. Martin, B.; McMahon, M.E.; Riposo, J.; Kallimani, J.G.; Bohman, A.; Ramos, A.; Schendt, A. A Strategic Assessment of the Future of U.S. Navy Ship Maintenance: Challenges and Opportunities; RAND: Santa Monica, CA, USA, 2007.

6. Osterrieder, P.; Budde, L.; Friedli, T. The smart factory as a key construct of industry 4.0: A systematic literature review. Int. J. Prod. Econ. 2020, 221, 107476. [CrossRef]

7. Mabkhot, M.M.; Al-Ahmari, A.M.; Salah, B.; Alkhalefah, H. Requirements of the smart factory system: A survey and perspective. Machines 2018, 6, 23. [CrossRef]

8. James, M.; Jimmy, I. Big Data Analytics for Smart Manufacturing: Case Studies in Semiconductor Manufacturing. Process 2017, 5, 39. [CrossRef]

9. Sjödin, D.R.; Parida, V.; Leksell, M.; Petrovic, A. Smart Factory Implementation and Process Innovation: A Preliminary Maturity Model for Leveraging Digitalization in Manufacturing Moving to smart factories presents specific challenges that can be addressed through a structured approach focused on people, processes, and technologies. Res. Technol. Manag. 2018, 61, 22-31. [CrossRef]

10. Wang, B.; Tao, F.; Fang, X.; Liu, C.; Liu, Y.; Freiheit, T. Smart Manufacturing and Intelligent Manufacturing: A Comparative Review. Engineering 2021, 7, 738-757. [CrossRef]

11. Mittal, S.; Khan, M.A.; Romero, D.; Wuest, T. Smart manufacturing: Characteristics, technologies and enabling factors. Proc. Inst. Mech. Eng. Part B J. Eng. Manuf. 2019, 233, 1342-1361. [CrossRef]

12. Zhong, R.Y.; Xu, X.; Klotz, E.; Newman, S.T. Intelligent Manufacturing in the Context of Industry 4.0: A Review. Engineering 2017, 3, 616-630. [CrossRef]

13. Kerin, M.; Pham, D.T. A review of emerging industry 4.0 technologies in remanufacturing. J. Clean. Prod. 2019, 237. [CrossRef]

14. Vogel-Heuser, B.; Bauernhansl, T.; ten Hompel, M. (Eds.) Handbuch Industrie 4.0 Bd.4, Allgemeine Grundlagen, 2nd ed.; Springer: Berlin/Heidelberg, Germany, 2017; ISBN 978-3-662-53254-6.

15. Dornhöfer, M.; Sack, S.; Zenkert, J.; Fathi, M. Simulation of Smart Factory Processes Applying Multi-Agent-Systems-A Knowledge Management Perspective. J. Manuf. Mater. Process. 2020, 4, 89. [CrossRef]

16. Bokrantz, J.; Skoogh, A.; Berlin, C.; Wuest, T.; Stahre, J. Smart Maintenance: An empirically grounded conceptualization. Int. J. Prod. Econ. 2020, 223, 107534. [CrossRef]

17. Capestro, M.; Kinkel, S. Industry 4.0 and Knowledge Management: A Review of Empirical Studies; Springer International Publishing: Berlin/Heidelberg, Germany, 2020; ISBN 978-3-030-43589-9_2.

18. Mantravadi, S.; Møller, C.; Li, C.; Schnyder, R. Design choices for next-generation IIoT-connected MES/MOM: An empirical study on smart factories. Robot. Comput.-Integr. Manuf. 2021, 73, 102225. [CrossRef]

19. Lang, V.; Weingarten, S.; Wiemer, H.; Scheithauer, U.; Glausch, F.; Johne, R.; Michaelis, A.; Ihlenfeldt, S. Process Data-Based Knowledge Discovery in Additive Manufacturing of Ceramic Materials by Multi-Material Jetting (CerAM MMJ). J. Manuf. Mater. Process 2020, 4, 74. [CrossRef]

20. Prometheus Group Homepage. Available online: https://www.prometheusgroup.com/posts/5-transformational-trendsreshaping-industrial-maintenance (accessed on 10 October 2021).

21. The Manufacturer Homepage. Available online: https://www.themanufacturer.com/press-releases/erp-solutions-supportindustry-4-0 (accessed on 10 October 2021).

22. Noman, M.A.; Nasr, E.S.A.; Al-Shayea, A.; Kaid, H. Overview of predictive condition based maintenance research using bibliometric indicators. J. King Saud Univ.-Eng. Sci. 2019, 31, 355-367. [CrossRef]

23. Goti, A.; Oyarbide-Zubillaga, A.; Alberdi, E.; Sanchez, A.; Garcia-Bringas, P. Optimal Maintenance Thresholds to Perform Preventive Actions by Using Multi-Objective Evolutionary Algorithms. Appl. Sci. 2019, 9, 3068. [CrossRef]

24. Balogh, Z.; Gatial, E.; Barbosa, J.; Leitao, P.; Matejka, T. Reference Architecture for a Collaborative Predictive Platform for Smart Maintenance in Manufacturing. In Proceedings of the IEEE 22nd International Conference on Intelligent Engineering Systems (INES), Las Palmas de Gran Canaria, Spain, 21-23 June 2018. [CrossRef]

25. Aksa, K.; Aitouche, S.; Bentoumi, H.; Sersa, I. Developing a Web Platform for the Management of the Predictive Maintenance in Smart Factories. Wirel. Pers. Commun. 2021, 119, 1-29. [CrossRef]

26. Gopalakrishnan, M.; Skoogh, A.; Salonen, A.; Asp, M. Machine criticality assessment for productivity improvement. Int. J. Product. Perform. Manag. 2019, 68, 858-878. [CrossRef]

27. Pech, M.; Vrchota, J.; Bednář, J. Predictive Maintenance and Intelligent Sensors in Smart Factory: Review. Sensors 2021, 21, 1470. [CrossRef] [PubMed]

28. Fusko, M.; Rakyta, M.; Krajcovic, M.; Dulina, L.; Gaso, M.; Grznar, P. Basics of Designing Maintenance Processes in Industry 4.0. MM Sci. J. 2018, 1, 2252-2259. [CrossRef] 
29. Biedermann, H.; Kinz, A. Lean Smart Maintenance-Value Adding, Flexible, and Intelligent Asset Management. BHM Berg-Und Hüttenmännische Mon. 2019, 164, 13-18. [CrossRef]

30. Moeuf, A.; Pellerin, R.; Lamouri, S.; Tamayo-Giraldo, S.; Barbaray, R. The industrial management of SMEs in the era of Industry 4.0. Int. J. Prod. Res. 2018, 56, 1118-1136. [CrossRef]

31. Masood, T.; Sonntag, P. Industry 4.0: Adoption challenges and benefits for SMEs. Comput. Ind. 2020, 121, 103261. [CrossRef]

32. Strozzi, F.; Colicchia, C.; Creazza, A.; Noè, C. Literature review on the 'smart factory' concept using bibliometric tools. Int. J. Prod. Res. 2017, 55, 6572-6591. [CrossRef]

33. Shin, S.M.; Chang, C.W.; Kown, S.B.; Kim, B.K. Smart Factory of Naval Maintenance Depot Construction concept and development direction. J. Soc. Nav. Archit. Korea 2020, 57, 27-30.

34. Resman, M.; Turk, M.; Herakovic, N. Methodology for planning smart factory. Procedia CIRP 2020, 97, 401-406. [CrossRef]

35. Zheng, P.; Wang, H.; Sang, Z.; Zhong, R.Y.; Liu, Y.; Liu, C.; Mubarok, K.; Yu, S.; Xu, X. Smart manufacturing systems for Industry 4.0: Conceptual framework, scenarios, and future perspectives. Front. Mech. Eng. 2018, 13, 137-150. [CrossRef]

36. Burke, R.; Laaper, S.; Hartigan, M.; Mussomeli, A.; Sniderman, B. The Smart Factory Responsive, Adaptive, Connected Manufacturing A Deloitte Series on Industry 4.0, Digital Manufacturing Enterprises, and Digital Supply Networks; (n.d.); Deloitte University Press: Westlake, TX, USA, 2017.

37. Automation World Home Page. Three Steps to Start the Smart Manufacturing Journey. Available online: https://www. automationworld.com/products/software/blog/13316170/three-steps-to-start-the-smart-manufacturing-journey (accessed on 17 October 2016).

38. Yoon, S.C.; Um, J.; Suh, S.H.; Stroud, I.; Yoon, J.S. Smart Factory Information Service Bus (SIBUS) for manufacturing application: Requirement, architecture and implementation. J. Intell. Manuf. 2019, 30, 363-382. [CrossRef]

39. Longo, F.; Nicoletti, L.; Padovano, A. Smart operators in industry 4.0: A human-centered approach to enhance operators' capabilities and competencies within the new smart factory context. Comput. Ind. Eng. 2017, 113, 144-159. [CrossRef]

40. Shariatzadeh, N.; Lundholm, T.; Lindberg, L.; Sivard, G. Integration of Digital Factory with Smart Factory Based on Internet of Things. Procedia CIRP 2016, 50, 512-551. [CrossRef]

41. Erasmus, J.; Grefen, P.; Vanderfeesten, I.; Traganos, K. Smart hybrid manufacturing control using cloud computing and the internet-of-things. Machines 2018, 6, 62. [CrossRef]

42. Hermann, M.; Pentek, T.; Otto, B. Design Principles for Industrie 4.0 Scenarios. In Proceedings of the 201649 th Hawaii International Conference on System Sciences (HICSS), Koloa, HI, USA, 5-8 January 2016. [CrossRef]

43. Gorecky, D.; Weyer, S.; Hennecke, A.; Zühlke, D. Design and Instantiation of a Modular System Architecture for Smart Factories. IFAC-Papers 2016, 49, 79-84. [CrossRef]

44. Li, Q.; Tang, Q.; Chan, I.; Wei, H.; Pu, Y.; Jiang, H.; Li, J.; Zhou, J. Smart manufacturing standardization: Architectures, reference models and standards framework. Comput. Ind. 2018, 101, 91-106. [CrossRef]

45. Zeid, A.; Sundaram, S.; Moghaddam, M.; Kamarthi, S.; Marion, T. Interoperability in smart manufacturing: Research challenges. Machines 2019, 7, 21. [CrossRef]

46. Zhang, D.; Wan, J.; Hsu, C.H.; Rayes, A. Industrial technologies and applications for the Internet of Things. Comput. Netw. 2016, 101, 1-4. [CrossRef]

47. Shu, Z.; Wan, J.; Zhang, D.; Li, D. Cloud-Integrated Cyber-Physical Systems for Complex Industrial Applications. Mob. Netw. Appl. 2016, 21, 865-878. [CrossRef]

48. Chen, B.; Wan, J.; Shu, L.; Li, P.; Mukherjee, M.; Yin, B. Smart Factory of Industry 4.0: Key Technologies, Application Case, and Challenges. IEEE Access 2018, 6, 6505-6519. [CrossRef]

49. Hamzeh, R.; Xu, X. Technology selection methods and applications in manufacturing: A review from 1990 to 2017. Comput. Ind. Eng. 2019, 138, 106123. [CrossRef]

50. Kagermann, H.; Walhster, W.; Helbig, J. Recommendations for Implementing the Strategic Initiative INDUSTRIE 4.0: Securing the Future of German Manufacturing Industry; Final Report of the Industrie 4.0 Working Group; Forschungsunion Deutsche Wissenschaft, 2013. Available online: https:/ / www.din.de/blob/76902/e8cac883f42bf28536e7e8165993f1fd/recommendations-for-implementingindustry-4-0-data.pdf (accessed on 10 October 2021).

51. Žižek, S.Š.; Nedelko, Z.; Mulej, M.; Čič, Ž.V. Key Performance Indicators and Industry 4.0—A Socially Responsible Perspective. Our Econ. 2020, 66, 22-35. [CrossRef]

52. Büchi, G.; Cugno, M.; Castagnoli, R. Smart factory performance and Industry 4.0. Technol. Forecast. Soc. Chang. 2020, 150, 119790. [CrossRef]

53. Wikitude Home Page. Wikitude Augmented Reality: The World's Leading Cross-Platform AR SDK. Available online: https: //www.wikitude.com (accessed on 10 October 2021).

54. MSS Home Page. Available online: https:/ www.mss.go.kr/site/smba/ex/bbs $/$ View.do?cbIdx=86\&bcIdx=1011893\&parentSeq= 1011893, (accessed on 10 October 2021). 